\title{
Association between levels of vitamin $D$ and inflammatory markers in healthy women
}

This article was published in the following Dove Press journal:

Journal of Inflammation Research

27 April 2016

Number of times this article has been viewed

\section{Fawaz Azizieh' \\ Khulood O Alyahya ${ }^{2}$ \\ Raj Raghupathy ${ }^{3}$}

'Department of Mathematics and Natural Sciences, Gulf University for Science and Technology, Kuwait City, Kuwait; ${ }^{2}$ Science Department, College of Basic Education, Public Authority for Applied Education and Training, Kuwait City, Kuwait; ${ }^{3}$ Department of Microbiology, Faculty of Medicine, Kuwait University, Kuwait City, Kuwait
Correspondence: Fawaz Y Azizieh Department of Mathematics and Natural Sciences, Gulf University for Science and Technology, Block 5, Building I, Mubarak Al-Abdullah Area, West Mishref, Kuwait City, Kuwait

Tel +965 25307499

Email Azizieh.f@gust.edu.kw
Background: No one can deny that the biological importance of vitamin D is much beyond its classical role in bone metabolism. Several recent publications have highlighted its potential role in the functioning of the immune system. The overall objective of this study was to look into possible correlations between levels of vitamin D and inflammatory markers in sera of healthy adult women. These markers included proinflammatory cytokines (interleukin [IL]-1 $\beta$, IL-6, IL-8, IL-17, interferon [IFN]- $\gamma$, and tumor necrosis factor [TNF]- $\alpha$ ), anti-inflammatory cytokines (IL-4, IL-10, and IL-13), as well as C-reactive protein (CRP) as a general indicator of inflammation.

Methods: Venous blood samples were collected from 118 healthy adult women and serum levels of vitamin D, CRP, proinflammatory cytokines (IL-1 $\beta$, IL-6, IL-8, IL-17, IFN- $\gamma$, and TNF- $\alpha$ ), and anti-inflammatory cytokines (IL-4, IL-10, and IL-13) were measured.

Results: There were no significant direct correlations between serum levels of vitamin D and any of the inflammatory markers measured. However, subjects with deficient levels of vitamin D and high CRP produced significantly higher levels of the proinflammatory cytokines (TNF- $\alpha$ and IL-8) as compared to subjects with low CRP levels with nondeficient and deficient levels of vitamin D. Further, the anti-inflammatory/proinflammatory ratios suggest a role of vitamin D in maintaining an anti-inflammatory environment at low levels of CRP, an association that is weaker at high CRP levels in subjects with subclinical inflammatory situations.

Conclusion: These data point to a possible role of vitamin D as a contributing factor in balancing cytokines toward an anti-inflammatory role in inflammatory situations.

Keywords: vitamin D, cytokines, adult women, CRP, Kuwait

\section{Introduction}

Hypovitaminosis D is a disorder prevalent in developing countries, with ranges between $30 \%$ and $90 \%$, according to the cutoff values used within different regions. ${ }^{1}$ Although low levels of vitamin D have been found in both males and females, the prevalence is higher among females. A series of recent studies on adolescent females revealed that about $81 \%$ of Saudi, ${ }^{2} 51.4 \%$ of Qatari, ${ }^{3} 86 \%$ of Kuwaiti, ${ }^{4}$ and $72.1 \%$ of Iranian ${ }^{5}$ females have vitamin D levels $<25 \mathrm{nmol} / \mathrm{L}$. It is also reported that $84 \%$ of vitamin D-deficient Lebanese adults $^{6}$ and $63 \%$ of vitamin D-deficient Jordanian volunteers were females. ${ }^{7}$ Another study from Kuwait revealed that $40 \%$ of mothers and $60 \%$ of their neonates had undetectably low vitamin D levels (0-25 nmol/L) at delivery. ${ }^{8}$

Therefore, vitamin D deficiency is considered a silent epidemic for a very good reason - most people are not even aware that it exists. However, this silent epidemic is a contributing factor for many chronic debilitating diseases other than poor bone 
development. ${ }^{9}$ Vitamin D deficiency has been associated with breast and colon cancer, asthma, cardiovascular diseases, preeclampsia, multiple sclerosis, inflammatory bowel diseases, systemic lupus erythematosus, rheumatoid arthritis, and others (reviewed in Wobke et $\mathrm{al}^{10}$ ). Furthermore, overwhelming scientific evidence suggests that maintenance of an adequate vitamin $\mathrm{D}$ level is essential in the prevention of a wide variety of health disorders, ${ }^{9,11,12}$ as it modulates multiple genes, immune, and inflammatory responses. ${ }^{13,14}$ The potential role of vitamin D in functioning of the immune system is supported by identifying vitamin $\mathrm{D}$ receptors in most immune system cells including macrophages, neutrophils, dendritic cells, and T-lymphocytes. ${ }^{15}$ Accordingly, vitamin D status is thought to be one of the key parameters contributing to healthy functioning of the immune system, ${ }^{15,16}$ including regulation of the cytokine environment. ${ }^{13}$

Cytokines are cell signaling molecules that are essential to mount and modulate all immune responses. They circulate in picomolar concentrations and may increase almost 1,000-fold in response to immune challenges such as inflammation. While a group of these cytokines are known to dominate in inflammatory situations (proinflammatory), others serve to reduce inflammation and promote healing (anti-inflammatory).

There are several lines of evidence to support a potential role of vitamin $\mathrm{D}$ in enhancing the anti-inflammatory cytokine balance. These include in vivo and in vitro experiments where vitamin $\mathrm{D}$ was shown to enhance the production of anti-inflammatory cytokines (transforming growth factor [TGF] $\beta-1$ and interleukin [IL]-4) ${ }^{17}$ and to reduce the production of the proinflammatory ones (IL-6, interferon-gamma $[$ IFN- $\gamma]$, IL-2, and tumor necrosis factor [TNF]- $\alpha) .{ }^{18,19}$ Vitamin D was also shown to be essential for normal macrophage functions, while its insufficiency was associated with impaired chemotaxis, phagocytosis, ${ }^{20}$ and upregulation of monocyte toll-like receptors, which are known inducers of inflammation. ${ }^{21}$

Clinically, vitamin D deficiency was found to be associated with several autoimmune inflammatory diseases such as multiple sclerosis, type I diabetes, and rheumatoid arthritis, ${ }^{12,22}$ while its supplementation was found to improve cytokine profiles in patients with chronic diseases such as congestive heart failure, rheumatoid arthritis, and osteoporosis..$^{23,24}$ Other reports also support a protective role of vitamin D in reducing the likelihood of developing inflammatory rheumatoid arthritis ${ }^{25}$ as well as the risk of certain infectious diseases. ${ }^{26}$
On balance, the published literature supports the need for further inquiry into vitamin D status and its implications for the immune system. Thus, our overall objective of this study was to find the relationship between vitamin D status and inflammatory markers in sera of healthy, Kuwaiti, adult women. These included inflammatory cytokines (IL-1 $\beta$, IL-6, IL-8, IL-17, IFN- $\gamma$, and TNF- $\alpha$ ), anti-inflammatory cytokines (IL-4, IL-10, and IL-13), as well as C-reactive protein (CRP) as a general indicator of inflammation.

\section{Methods}

\section{Subjects}

Invitation letters were sent to the mothers of students - from a previous study ${ }^{4}$ - who were recruited from schools located in each governorate in Kuwait. In addition, female students in the College of Basic Education, Public Authority for Applied Education and Training, Kuwait, were also invited to participate. A total of 118 healthy adult women aged 19-47 years were recruited during the period of December 2011 to March 2012. In order to limit the effect of the heterogeneous composition of the study population in terms of variation in ethnicity, race, lifestyle, and dietary habits, this study included only Kuwaiti citizens. All subjects were nonpregnant, non-breast-feeding, free from chronic diseases known to interfere with vitamin D metabolism, and not taking any medications or vitamin/mineral supplements/injections for the past 6 months. All participants gave their written consent, underwent clinical assessment, and were included in the study as apparently healthy individuals. The study was granted the ethical approval by the Joint Committee for the Protection of Human Subjects in Research, including Kuwait Institute for Medical Specialization - Ministry of Health and AbdulMihsin Al-Abdulrezzag Health Sciences Center - Kuwait University, Kuwait.

\section{Blood sampling}

Venous blood samples were collected into vacutainer tubes and allowed to clot at room temperature for 30 minutes. The coagulated blood was centrifuged for 10 minutes at 3,000 $\times g$; the serum was aliquoted into sterile tubes and stored frozen till analysis.

\section{Measurement of vitamin D and CRP}

Quantitation of serum [25(OH)D] was performed using the radioimmunoassay commercial kit (IDS Inc., Draper, UT, USA) that detects $25(\mathrm{OH}) \mathrm{D}$ in the range of 5-300 nmol/L with an inter- and intra-assay coefficient of variation of $3.43 \%$ 
and $5.44 \%$, respectively. The cutoff to define a nondeficient circulating concentration of $25(\mathrm{OH}) \mathrm{D}$ was taken to be $25 \mathrm{nmol} / \mathrm{L}$, and concentrations lower than that were categorized as deficient. ${ }^{27,28}$ Subjects were therefore classified as nondeficient $(\mathrm{N})$ if their serum vitamin $\mathrm{D}$ level was $\geq 25$ $\mathrm{nmol} / \mathrm{L}$ or deficient (D) if the level was $<25 \mathrm{nmol} / \mathrm{L}$.

High-sensitivity CRP was measured in the sera by rate nephelometry using the IMMAGE Immunochemistry Systems from Beckman Coulter (Galway, Ireland). The cutoff to define a nondeficient serum level of CRP was $1 \mathrm{mg} / \mathrm{dL}$. Subjects were classified as low (L) if the serum level of CRP was $<1 \mathrm{mg} / \mathrm{dL}$ or as high $(\mathrm{H})$ if the serum level of CRP was $\geq 1 \mathrm{mg} / \mathrm{dL}$. The detection sensitivity of the assay was $0.1 \mathrm{mg} / \mathrm{dL}$.

\section{Cytokine analysis}

A multiplex enzyme-linked immunosorbent assay-based immunoassay, containing dyed microspheres conjugated with a monoclonal antibody specific for a target protein, was used according to the manufacturer's instructions (Merck Millipore, Darmstadt, Germany). Soluble molecules were measured using Human Cytokine commercially available kits (HCYTOMAG-60K; Merck Millipore) 9-Plex panel: IL-1 $\beta$, IL-4, IL-6, IL-8, IL-10, IL-17, IL-13, IFN- $\gamma$, and TNF- $\alpha$. Each experiment was performed in duplicate, using the same procedure described by the manufacturer. Serum concentrations of all cytokines were determined using a MAGPIX array reader (Luminex, Austin, TX, USA) that quantitates multiplex immunoassays in a 96-well format with very small sample volumes. The analyte concentration was calculated using a standard curve, with Luminex Manager Software (Luminex Software Inc., Riverside, CA, USA). The detection sensitivity of the assays was $0.7 \mathrm{pg} / \mathrm{mL}$ for TNF$\alpha ; 0.8 \mathrm{pg} / \mathrm{mL}$ for IL-1 $\beta$, IL-4, IL-6, IL-8, IL-13, IL-17, and IFN- $\gamma$, and $1.1 \mathrm{pg} / \mathrm{mL}$ for IL-6.

\section{Statistical methods}

Data and statistical analysis was done using SPSS 22 software (IBM Corporation, Armonk, NY, USA). Normality distribution of data was first determined by Kolmogorov-Smirnov test. Continuous variables were compared with the MannWhitney $U$-test, and categorical variables were compared using Pearson's $\chi^{2}$-square test. Linear and univariate multiple regression models were used to determine the relationships between serum $25(\mathrm{OH}) \mathrm{D}$ and various serum inflammatory markers. $P$-value of less than 0.05 was considered statistically significant for all tests.

\section{Results}

The overall mean concentration of serum 25(OH)D for all the 118 subjects was $28.9 \pm 32.1 \mathrm{nmol} / \mathrm{L}$ (range from 0 to 158 $\mathrm{nmol} / \mathrm{L}$ ), while that of CRP was $0.6 \pm 0.68 \mathrm{mg} / \mathrm{dL}$ (range from 0.1 to $4.89 \mathrm{mg} / \mathrm{dL}$ ). It is worth mentioning that IL-6, IL-10, and IL-13 were not measureable in any of the sera tested.

There were no significant correlations between serum levels of vitamin D and CRP, or between levels of vitamin D and any of the cytokines measured in the sera. However, sera levels of CRP correlated significantly with the proinflammatory cytokine IL-8 $(r=0.185, P=0.048)$, but there were no other significant correlations with other measured analytes.

Patients were further classified into two groups: (N, n=29, $24.6 \%$ ); and (D, $n=89,75.4 \%$ ). The demographic data and median values of measured parameters of these two groups are shown in Table 1.

Subjects in the deficient vitamin D group were statistically significantly younger than those with nondeficient levels $(P=0.004)$. However, there were no statistically significant differences between the two groups with regard to serum levels of CRP or any of the measured cytokines (Table 1).

Based on the serum level of CRP, subjects were studied after classifying them into two groups: $(n=101,85.6 \%)$ and $\mathrm{H}(\mathrm{n}=17,14.4 \%)$. The demographic data and median values of measured parameters of these two groups are shown in Table 2.

Subjects in the high levels of CRP group were statistically significantly older than those in the low CRP group $(P=0.020)$. Further, sera from subjects with high levels of CRP had a statistically significantly higher median level

Table I Age, CRP, and cytokine median values in subjects with deficient and nondeficient levels of vitamin $D$

\begin{tabular}{llll}
\hline & $\begin{array}{l}\text { Deficient } \\
\text { vitamin D } \\
\text { (level } \\
<25 \text { nmol/L) }\end{array}$ & $\begin{array}{l}\text { Nondeficient } \\
\text { vitamin D } \\
\text { (level } \\
\geq 25 \text { nmol/L) }\end{array}$ & P-value \\
\hline Number & 89 & 29 & \\
Age (years) & 26 & 38 & 0.004 \\
Vitamin D (nmol/L) & 15.0 & 75.0 & 0.000 \\
CRP $(\mathrm{mg} / \mathrm{dL})$ & 0.38 & 0.51 & 0.669 \\
IL-I $\beta(\mathrm{pg} / \mathrm{mL})$ & 0.24 & 0.29 & 0.749 \\
IFN- $\gamma(\mathrm{pg} / \mathrm{mL})$ & 10.17 & 13.78 & 0.165 \\
TNF- $\alpha(\mathrm{pg} / \mathrm{mL})$ & 9.90 & 9.75 & 0.724 \\
IL-8 $(\mathrm{pg} / \mathrm{mL})$ & 13.71 & 14.12 & 0.822 \\
IL-I7 $(\mathrm{pg} / \mathrm{mL})$ & 3.95 & 6.61 & 0.594 \\
IL-4 $(\mathrm{pg} / \mathrm{mL})$ & 132.40 & 240.50 & 0.392 \\
\hline A & &
\end{tabular}

Abbreviations: CRP, C-reactive protein; IL, interleukin; IFN, interferon; TNF, tumor necrosis factor. 
Table 2 Age, vitamin D, and cytokine median values in subjects with low and high levels of CRP

\begin{tabular}{llll}
\hline & $\begin{array}{l}\text { Low } \\
\text { CRP level } \\
\text { (<I mg/dL) }\end{array}$ & $\begin{array}{l}\text { High } \\
\text { CRP level } \\
\text { ( } \geq \text { I mg/dL) }\end{array}$ & \\
\hline Number & 10 -value \\
Age (years) & 27 & 17 & \\
Vitamin D (nmol/L) & 16.0 & 40 & 0.020 \\
CRP $(\mathrm{mg} / \mathrm{dL})$ & 0.33 & 18.0 & 0.940 \\
IL-I $\beta(\mathrm{pg} / \mathrm{mL})$ & 0.42 & 1.54 & 0.000 \\
IFN- $\gamma(\mathrm{pg} / \mathrm{mL})$ & 10.16 & 0.00 & 0.042 \\
TNF- $\alpha(\mathrm{pg} / \mathrm{mL})$ & 9.72 & 13.78 & 0.249 \\
IL-8 $(\mathrm{pg} / \mathrm{mL})$ & 12.95 & 12.25 & 0.090 \\
IL-I7 $(\mathrm{pg} / \mathrm{mL})$ & 4.23 & 18.00 & 0.106 \\
IL-4 $(\mathrm{pg} / \mathrm{mL})$ & 155.98 & 3.58 & $0.97 \mid$ \\
\hline
\end{tabular}

Abbreviations: CRP, C-reactive protein; IL, interleukin; IFN, interferon; TNF, tumor necrosis factor.

of IL-1 $\beta$ as compared to sera from subjects with low levels of CRP $(P=0.042)$ (Table 2).

We further stratified the subjects and compared the cytokine levels in the following four groups:

Group 1: subjects with nondeficient levels of vitamin D and

low levels of CRP (denoted as NL, $\mathrm{n}=23,19.5 \%$ ),

Group 2: subjects with nondeficient levels of vitamin D and

high levels of CRP (denoted as NH, $\mathrm{n}=6,5.1 \%$ ),

Group 3: subjects with deficient levels of vitamin D and low

levels of CRP (denoted as DL, $\mathrm{n}=78,66.1 \%$ ), and

Group 4: subjects with deficient levels of vitamin D and high

levels of CRP (denoted as DH, $\mathrm{n}=11,9.3 \%$ ).

Figure 1 presents the median levels of IL-1 $\beta$, IL-4, IL-8, and TNF- $\alpha$ in each of these four groups.

Significantly higher levels of IL-4 were present in sera of subjects in NL group (nondeficient levels of vitamin $\mathrm{D}$ and low levels of CRP) as compared to subjects in NH $(P=0.046)$, DL $(P=0.047)$, and DH $(P=0.025)$ groups (Figure $1 \mathrm{~A})$.

On the other hand, serum IL-1 $\beta$ levels were significantly lower in DH group as compared to the NL $(P=0.013), \mathrm{NH}$ $(P=0.025)$, and DL $(P=0.016)$ groups (Figure 1B). Further, DH group had statistically significantly higher IL-8 median level as compared to $\mathrm{DL}$ group $(P=0.039)$ and higher TNF- $\alpha$ levels as compared to $\mathrm{NL}$ group $(P=0.011)$ (Figure $1 \mathrm{C}$ and $\mathrm{D}$ ). There were no statistically significant differences between the four groups with respect to sera levels of IFN- $\gamma$ and IL-17 (data not shown).

In order to evaluate the cytokine balance in each of the groups, we calculated the cytokine ratio of the antiinflammatory cytokine (IL-4) to the proinflammatory ones (TNF- $\alpha$, IFN- $\gamma$, IL-8, and IL-17), listed in Table 3. As expected, subjects with low CRP levels had higher ratios as compared
Table 3 Ratio of anti-inflammatory/proinflammatory cytokines in stratified groups

\begin{tabular}{lllll}
\hline Group & IL-4/TNF- $\alpha$ & IL-4/IFN- $\boldsymbol{\gamma}$ & IL-4/IL-8 & IL-4/IL-I 7 \\
\hline $\mathrm{NL}$ & 37.5 & 25.2 & 27.2 & 53.5 \\
$\mathrm{NH}$ & 7.8 & 6.1 & 4.2 & 12.5 \\
$\mathrm{DL}$ & 14.7 & 14.2 & 10.9 & 34.9 \\
$\mathrm{DH}$ & 6.7 & 4.2 & 5.0 & 27.3 \\
\hline
\end{tabular}

Abbreviations: IL, interleukin; IFN, interferon; TNF, tumor necrosis factor; $\mathrm{NL}$, nondeficient levels of vitamin $\mathrm{D}$ and low levels of CRP; $\mathrm{NH}$, nondeficient levels of vitamin $D$ and high levels of CRP; $D L$, deficient levels of vitamin $D$ and low levels of CRP; DH, deficient levels of vitamin D and high levels of CRP; CRP, C-reactive protein.

to those with high CRP levels. However, among both groups with low CRP levels, subjects with nondeficient vitamin D had higher anti-inflammatory/proinflammatory ratios in all cytokine combinations. On the other hand, among the groups with high CRP levels, the differences in ratios were not as prominent.

\section{Discussion}

Despite ample sunshine, several reports from the Middle East highlighted the prevalence of hypovitaminosis D. These include reports from Jordan, ${ }^{7}$ Lebanon, ${ }^{6}$ Saudi Arabia, ${ }^{29}$ United Arab Emirates, ${ }^{30}$ and Kuwait. ${ }^{4,8}$ Although Kuwait is blessed with ambient sunshine all around the year, it is possible that the life style and the harsh hot weather during the long summer discourage daily sun exposure needed to maintain adequate vitamin D levels. In this study, subjects with vitamin D deficiency were statistically significantly younger compared to subjects with nondeficient levels. It is possible that with age, people are more aware and concerned with their health and accordingly adjust their lifestyle and diet to maintain higher levels of vitamin D.

There is no absolute agreement on the optimal level of serum vitamin D to date. The World Health Organization and the Nordic Council of Ministers ${ }^{28}$ agreed on marking sufficiency at $50 \mathrm{nmol} / \mathrm{L}$, but defined deficiency as below $25 \mathrm{nmol} / \mathrm{L}$. Ranges between 25 and $50 \mathrm{nmol} / \mathrm{L}$ remain controversial and are reported as insufficient levels, as other organizations and societies found that levels higher than $50 \mathrm{nmol} / \mathrm{L}$ were needed for optimal health. ${ }^{31}$ In our study, only eight subjects had serum levels of vitamin $\mathrm{D}$ in the range of $25-50 \mathrm{nmol} / \mathrm{L}$, while others had levels that were either $<25 \mathrm{nmol} / \mathrm{L}$ or $>50 \mathrm{nmol} / \mathrm{L}$. Therefore, we used the $25 \mathrm{nmol} / \mathrm{L}$ cutoff to group the subjects as nondeficient or deficient.

CRP is one of the "acute-phase proteins" produced by the liver. In inflammatory responses, serum levels of CRP may rise up to 60-fold, in as fast as 6 hours after the onset 
A

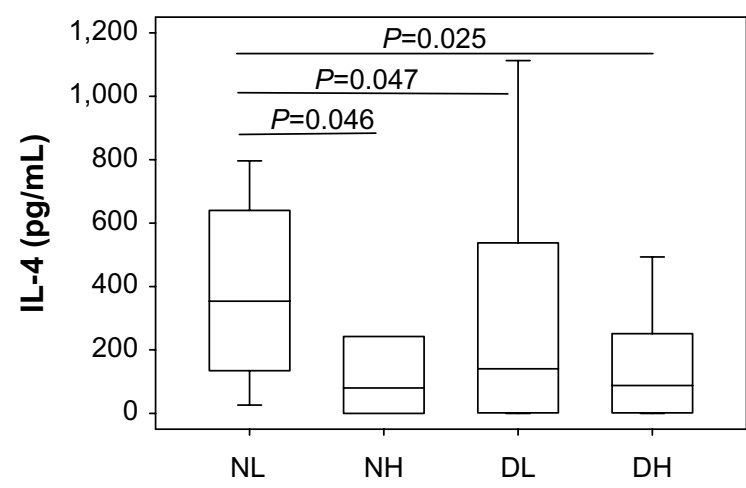

C

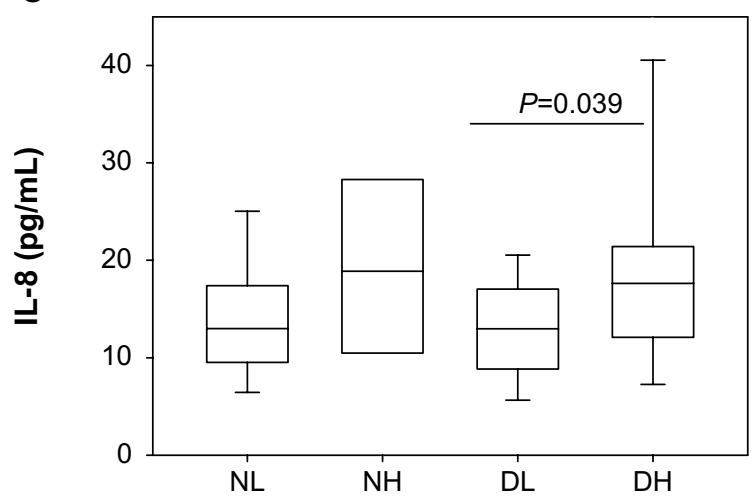

B

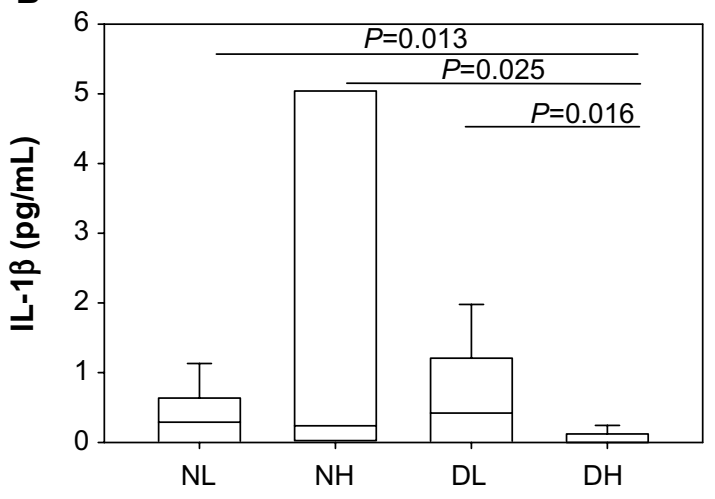

D

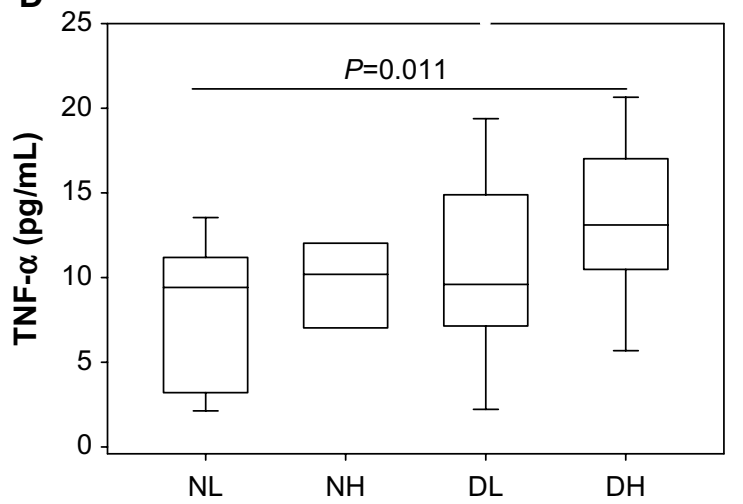

Figure I Median serum levels of cytokines in subject groups.

Abbreviations: IL, interleukin; TNF, tumor necrosis factor; NL, nondeficient levels of vitamin D and low levels of CRP; NH, nondeficient levels of vitamin D and high levels of CRP; DL, deficient levels of vitamin D and low levels of CRP; DH, deficient levels of vitamin D and high levels of CRP; CRP, C-reactive protein.

of inflammation. As CRP is much more specific than some of the other commonly used markers of inflammation such as the erythrocyte sedimentation rate, ${ }^{32}$ it is considered to be one of the best indicators of inflammation. ${ }^{33}$

Several studies have examined the relationship between vitamin D supplementation and serum levels of inflammatory markers such as CRP and cytokines. Some reports showed a positive relationship with IFN- $\gamma$ and IL- $10,{ }^{34}$ others showed a significant inverse relationship with serum TNF- $\alpha$ but no relationship with CRP, IL-6, or IL- $10,{ }^{35}$ or even no significant changes in serum levels of IL-4, IL-5, IL-10, IL-13, IL-2, IL-6, IFN- $\gamma$, or TNF- $\alpha \cdot{ }^{36-38}$ On the other hand, there is accumulating evidence to support an immunoregulatory role of vitamin $\mathrm{D},{ }^{21,26,39}$ and other studies ${ }^{10}$ are showing an association between vitamin $\mathrm{D}$ deficiency and a wide range of diseases. Such discrepancies in the literature encourage more studies both in healthy and diseased subjects to find out more about the possible relation between vitamin $\mathrm{D}$ and inflammation.

The current study did not find significant correlations between serum levels of vitamin D and cytokines measured or CRP. We predicted that subjects with nondeficient serum levels of vitamin D will have lower levels of proinflammatory cytokines and CRP, or higher levels of anti-inflammatory cytokines, as compared to subjects with deficient levels of serum vitamin D. ${ }^{34,35,40}$ However, we did not find cytokine levels to be significantly different between the two groups studied.

This encouraged us to further stratify our initial grouping of nondeficient $(\mathrm{N})$ versus deficient $(\mathrm{D})$ vitamin $\mathrm{D}$ serum levels to subgroups based on their serum levels of CRP; low (L) versus high $(\mathrm{H})$. This resulted in four subgroups: NL, NH, DL, and DH. Sera of NL group have the significantly highest concentration of the anti-inflammatory cytokine IL-4 as compared to all other groups. This may support a potential role of IL-4 in maintaining anti-inflammatory environment in healthy conditions at nondeficient vitamin $\mathrm{D}$ levels. This is further supported by the statistically significantly higher levels of the inflammatory cytokine TNF- $\alpha$ in the DH group as compared to NL group, Figure 1A and D.

On the other hand, DH group produced significantly higher levels of the proinflammatory cytokines (TNF- $\alpha$ and IL-8) as compared to NL and DL groups, respectively 
(Figure 1C and D). While TNF- $\alpha$ plays a well-established, key role in proinflammatory responses, IL-8 is known to induce chemotaxis. ${ }^{41} \mathrm{We}$ further reported significant correlation between serum levels of CRP and IL-8, which is consistent with what is reported by others. ${ }^{42,43}$ These data point to a possible role for vitamin D as a contributing factor in balancing the levels of cytokines toward an anti-inflammatory bias in inflammatory situations as indicated by CRP levels.

The anti-inflammatory/proinflammatory ratios depicted in Table 3 suggest a role of vitamin D in maintaining an antiinflammatory environment at low levels of CRP. However, this association is weaker at high CRP levels in subjects with subclinical inflammatory situations.

Further, the DH group had significantly lower levels of IL-1 $\beta$ as compared to the other three groups (NL, NH, and $\mathrm{DL} ; P=0.013,0.025$, and 0.016, respectively); Figure 1B. In other words, subjects with deficient vitamin $\mathrm{D}$ produced lower serum IL-1 $\beta$ as compared to those having nondeficient vitamin $\mathrm{D}$ (with or without high CRP levels). IL-1 $\beta$ is predominately produced by macrophages and is a critical mediator of tissue damage in chronic inflammatory diseases. ${ }^{44}$ Our data are in support of earlier research which demonstrated that vitamin D upregulates the production of IL-1 $\beta .^{45,46}$

In conclusion, while we do not observe significant direct correlations between vitamin D and serum cytokine profiles, stratifying the subjects based on their CRP levels shows an interesting possible relationship.

We recognize that this study has several limitations. Cytokines have a very short half-life in the periphery and should ideally be measured "locally", i.e. in tissues. The serum level of one cytokine is like the tip of an iceberg and may reflect a systemic change even for a subclinical condition. Cytokines function in complex networks, and the net balance controls the immune response. The study focused on cytokine levels in sera of adult women who were clinically assessed to be healthy. It would be of great interest to do similar studies on patients with other chronic diseases and inflammatory conditions. It should also be highlighted that data presented does not imply causation.

The prevalence of vitamin D deficiency in healthy Kuwaiti adult women is high, and increasing volume of research supports its association with a wide range of diseases. As cytokines are critical mediators of the immune system, further studies are needed to shed more light on the relationship between vitamin D and cytokine levels, as well as on the possible immunomodulatory action of vitamin D on the immune system. Such studies should include both healthy and diseased populations.

\section{Acknowledgment}

This research was supported and funded by Public Authority for Applied Education and Training (PAAET) project no. (BE-14-09).

\section{Disclosure}

The authors report no conflicts of interest in this work.

\section{References}

1. Arabi A, El Rassi R, El-Hajj Fuleihan G. Hypovitaminosis D in developing countries - prevalence, risk factors and outcomes. Nat Rev Endocrinol. 2010;6(10):550-561.

2. Siddiqui AM, Kamfar HZ. Prevalence of vitamin D deficiency rickets in adolescent school girls in Western region, Saudi Arabia. Saudi Med J. 2007;28(3):441-444.

3. Bener A, Al-Ali M, Hoffmann GF. High prevalence of vitamin D deficiency in young children in a highly sunny humid country: a global health problem. Minerva Pediatr. 2009;61(1):15-22.

4. Alyahya K, Lee WT, Al-Mazidi Z, Morgan J, Lanham-New S. Risk factors of low vitamin D status in adolescent females in Kuwait: implications for high peak bone mass attainment. Arch Osteoporos. 2014;9:178.

5. Hashemipour S, Larijani B, Adibi H, Javadi E, Sedaghat M, Pajouhi M. Vitamin D deficiency and causative factors in the population of Tehran. BMC Public Health. 2004;4:38.

6. Gannage-Yared MH, Chemali R, Yaacoub N, Halaby G. Hypovitaminosis $\mathrm{D}$ in a sunny country: relation to lifestyle and bone markers. J Bone Miner Res. 2000;15(9):1856-1862.

7. Mishal AA. Effects of different dress styles on vitamin D levels in healthy young Jordanian women. Osteoporos Int. 2001;12(11):931-935.

8. Molla AM, Al Badawi M, Hammoud MS, Shukkur M, Thalib L, Eliwa MS. Vitamin D status of mothers and their neonates in Kuwait. Pediatr Int. 2005;47(6):649-652.

9. Holick MF. Vitamin D deficiency. N Engl J Med. 2007;357(3): 266-281.

10. Wobke TK, Sorg BL, Steinhilber D. Vitamin D in inflammatory diseases. Front Physiol. 2014;5:244.

11. Lucas RM, Ponsonby AL. Considering the potential benefits as well as adverse effects of sun exposure: can all the potential benefits be provided by oral vitamin D supplementation? Prog Biophys Mol Biol. 2006;92(1):140-149.

12. Holick MF. Vitamin D: importance in the prevention of cancers, type 1 diabetes, heart disease, and osteoporosis. Am J Clin Nutr. 2004;79(3):362-371.

13. van Etten E, Mathieu C. Immunoregulation by 1,25-dihydroxyvitamin D3: basic concepts. J Steroid Biochem Mol Biol. 2005;97(1-2):93-101.

14. Cantorna MT, Mahon BD. D-hormone and the immune system. J Rheumatol Suppl. 2005;76:11-20.

15. White JH. Vitamin D signaling, infectious diseases, and regulation of innate immunity. Infect Immun. 2008;76(9):3837-3843.

16. Cantorna MT, Mahon BD. Mounting evidence for vitamin D as an environmental factor affecting autoimmune disease prevalence. Exp Biol Med (Maywood). 2004;229(11):1136-1142.

17. Cantorna MT, Woodward WD, Hayes CE, DeLuca HF. 1,25-dihydroxyvitamin D3 is a positive regulator for the two antiencephalitogenic cytokines TGF-beta 1 and IL-4. J Immunol. 1998;160(11):5314-5319.

18. Zhu Y, Mahon BD, Froicu M, Cantorna MT. Calcium and 1 alpha, 25-dihydroxyvitamin D3 target the TNF-alpha pathway to suppress experimental inflammatory bowel disease. Eur J Immunol. 2005; 35(1):217-224.

19. Lemire JM. Immunomodulatory role of 1, 25-dihydroxyvitamin D3. J Cell Biochem. 1992;49(1):26-31. 
20. Overbergh L, Decallonne B, Valckx D, et al. Identification and immune regulation of 25-hydroxyvitamin D-1-alpha-hydroxylase in murine macrophages. Clin Exp Immunol. 2000;120(1):139-146.

21. Sadeghi K, Wessner B, Laggner U, et al. Vitamin D3 down-regulates monocyte TLR expression and triggers hyporesponsiveness to pathogen-associated molecular patterns. Eur J Immunol. 2006;36(2): 361-370

22. Young AR, Walker SL. UV radiation, vitamin D and human health: an unfolding controversy introduction. Photochem Photobiol. 2005;81(6):1243-1245.

23. Inanir A, Ozoran K, Tutkak H, Mermerci B. The effects of calcitriol therapy on serum interleukin-1, interleukin-6 and tumour necrosis factoralpha concentrations in post-menopausal patients with osteoporosis. J Int Med Res. 2004;32(6):570-582.

24. Schleithoff SS, Zittermann A, Tenderich G, Berthold HK, Stehle P, Koerfer R. Vitamin D supplementation improves cytokine profiles in patients with congestive heart failure: a double-blind, randomized, placebo-controlled trial. Am J Clin Nutr. 2006;83(4):754-759.

25. Mursu J, Robien K, Harnack LJ, Park K, Jacobs DR Jr. Dietary supplements and mortality rate in older women: the Iowa Women's Health Study. Arch Intern Med. 2011;171(18):1625-1633.

26. Zasloff M. Fighting infections with vitamin D. Nat Med. 2006;12(4): 388-390.

27. Heaney RP. The vitamin D requirement in health and disease. J Steroid Biochem Mol Biol. 2005;97(1-2):13-19.

28. Lamberg-Allardt C, Brustad M, Meyer HE, Steingrimsdottir L. Vitamin D - a systematic literature review for the 5th edition of the Nordic Nutrition Recommendations. Food Nutr Res. 2013;57:22671.

29. Serenius F, Elidrissy AT, Dandona P. Vitamin D nutrition in pregnant women at term and in newly born babies in Saudi Arabia. J Clin Pathol. 1984;37(4):444-447.

30. Ainy E, Ghazi AA, Azizi F. Changes in calcium, 25(OH) vitamin D3 and other biochemical factors during pregnancy. $J$ Endocrinol Invest. 2006;29(4):303-307.

31. Spiro A, Buttriss JL. Vitamin D: an overview of vitamin D status and intake in Europe. Nutr Bull. 2014;39(4):322-350.

32. Ho KM, Towler SC. A comparison of eosinopenia and C-reactive protein as a marker of bloodstream infections in critically ill patients: a case control study. Anaesth Intensive Care. 2009;37(3):450-456.

33. Kao PC, Shiesh SC, Wu TJ. Serum C-reactive protein as a marker for wellness assessment. Ann Clin Lab Sci. 2006;36(2):163-169.
34. Barker T, Rogers VE, Levy M, et al. Supplemental vitamin D increases serum cytokines in those with initially low 25-hydroxyvitamin D: a randomized, double blind, placebo-controlled study. Cytokine. 2015;71(2):132-138.

35. Peterson CA, Heffernan ME. Serum tumor necrosis factor-alpha concentrations are negatively correlated with serum $25(\mathrm{OH}) \mathrm{D}$ concentrations in healthy women. J Inflamm (Lond). 2008;5:10.

36. Yusupov E, Li-Ng M, Pollack S, Yeh JK, Mikhail M, Aloia JF. Vitamin D and serum cytokines in a randomized clinical trial. Int J Endocrinol. 2010;2010:305054.

37. Sun X, Cao ZB, Zhang Y, Ishimi Y, Tabata I, Higuchi M. Association between serum 25-hydroxyvitamin $\mathrm{D}$ and inflammatory cytokines in healthy adults. Nutrients. 2014;6(1):221-230.

38. Garcia-Bailo B, Roke K, Mutch DM, El-Sohemy A, Badawi A. Association between circulating ascorbic acid, alpha-tocopherol, 25-hydroxyvitamin D, and plasma cytokine concentrations in young adults: a cross-sectional study. Nutr Metabol. 2012;9(1):102.

39. Cantorna MT. Vitamin D and multiple sclerosis: an update. Nutr Rev. 2008;66(10 Suppl 2):S135-S138.

40. Cantorna MT, Yu S, Bruce D. The paradoxical effects of vitamin D on type 1 mediated immunity. Mol Aspects Med. 2008;29(6):369-375.

41. Zhang JM, An J. Cytokines, inflammation, and pain. Int Anesthesiol Clin. 2007;45(2):27-37.

42. Kaminska J, Kowalska MM, Nowacki MP, Chwalinski MG, Rysinska A, Fuksiewicz M. CRP, TNF-alpha, IL-1ra, IL-6, IL-8 and IL-10 in blood serum of colorectal cancer patients. Pathol Oncol Res. 2000;6(1): 38-41.

43. Pine SR, Mechanic LE, Enewold L, et al. Increased levels of circulating interleukin 6, interleukin 8, C-reactive protein, and risk of lung cancer J Natl Cancer Inst. 2011;103(14):1112-1122.

44. Kinne RW, Stuhlmuller B, Burmester GR. Cells of the synovium in rheumatoid arthritis. Macrophages. Arthritis Res Ther. 2007;9(6):224.

45. Lee BN, Kim TH, Jun JB, et al. Upregulation of interleukin-1beta production by 1,25-dihydroxyvitamin $\mathrm{D}(3)$ in activated human macrophages. Mol Biol Rep. 2011;38(3):2193-2201.

46. Eklund D, Welin A, Andersson H, et al. Human gene variants linked to enhanced NLRP3 activity limit intramacrophage growth of Mycobacterium tuberculosis. J Infect Dis. 2014;209(5):749-753.
Journal of Inflammation Research

\section{Publish your work in this journal}

The Journal of Inflammation Research is an international, peer-reviewed open-access journal that welcomes laboratory and clinical findings on the molecular basis, cell biology and pharmacology of inflammation including original research, reviews, symposium reports, hypothesis formation and commentaries on: acute/chronic inflammation; mediators of inflamma-

\section{Dovepress}

tion; cellular processes; molecular mechanisms; pharmacology and novel anti-inflammatory drugs; clinical conditions involving inflammation. The manuscript management system is completely online and includes a very quick and fair peer-review system. Visit http://www.dovepress.com/ testimonials.php to read real quotes from published authors. 